\title{
John Dewey: dois textos, dois tempos, duas "vibes"
}

\section{Ana Mae Tavares Barbosa (USP) 1}

1 Professora Titular aposentada pela ECA-USP. Pós-Doutorado pelo Teachers College da Columbia University e pela University of Central England. Doutora em Educação Humanística pela Boston University. Mestre em Arte Educação pela Southern Connecticut State College. Especialista em Educação para Adultos pela Secretary of Education of New Haven. Curadora de Arte e autora de vários livros sobre Arte e Educação. Líder do Grupo de Pesquisa no CNPq: Design, Arte e Educação. Foi presidente da InSEA - International Society of Education Through Art (19901993), Anpap (Associação Nacional de Pesquisadores em Artes Plásticas), diretora do Museu de Arte Contemporânea MAC-USP (1987-1993), fundadora do CLEA Consejo Latinoamericano de Educación por el Arte e conselheira da Organização dos Estados Iberoamericanos. Recebeu diversos prêmios, entre eles, Grande Prêmio de Crítica da APCA, Edwin Ziegfeld International Award, Distinguished Fellow e Studies in Art Education Award Lecture (ambos da National Art Education Association - EUA), The Sir Herbert Read Award (UNESCO), Comenda da Ordem do Mérito Científico (Ministério de Ciências e Tecnologia), Ordem Nacional do Mérito Cultural (Ministério da Cultura), Prêmio Ícone da Educação do Istituto Europeo di Design, Prêmio Jabuti, Prêmio Itaú Cultural 30 anos, Condecoração de Reconhecimento em Educação (Câmara Brasileira de Cultura e Acadêmia de Ciências e Artes) e Doutor Honoris Causa pela UFPB e UFPE. Docente fundadora do PPG Design da Universidade Anhembi Morumbi. Tem experiência na área de Artes, com ênfase em Arte/Educação, atuando principalmente nos seguintes temas: Ensino da Arte e contextos metodológicos, História do Ensino da Arte e do Desenho, Ensino do Design, Administração de Arte, Interculturalidade, Pedagogia Visual, Estudos de Museus de Arte, Mediação Cultural e Estudos Visuais.Bolsista Produtividade, PQ2 CNPq.

E-mail: anamaebarbosa@gmail.com

ID Orcid: 0000-0002-4966-2043 


\section{Texto muito pessoal, numa "vibe" saudosista, 2021}

Depois de mais de um ano de enclausuramento para evitar contágio com o Coronavírus, apavorada de medo que minha filha que tem problemas respiratórios se contamine, estou sem energia para escrever artigos mas continuo adorando escrever sem compromisso acadêmico, sem ter de obedecer à ABNT. Jociele aceitou que eu escrevesse um ensaio ou um depoimento sobre a recepção de John Dewey no Brasil. Optei pelo depoimento.

Foi Paulo Freire, nos anos 50 no Recife, que fez eu me apaixonar pelas ideias de John Dewey. Paulo Freire me emprestou para ler o livro Meu credo Pedagógico. Daí em diante li tudo que estava traduzido em português. A Escola Nova no Brasil foi prodiga em boas traduções e publicações de John Dewey, principalmente como vocês sabem, graças à Anísio Teixeira. Curiosamente, só o seu livro Arte como Experiência, o mais importante para entendermos suas ideias acerca da Arte, ficou sem tradução no Brasil por mais ou menos 70 anos. Quando Dewey o publicou em 1934, Anísio Teixeira, curador informal de sua obra, estava totalmente envolvido com a criação da Universidade do Distrito Federal (criada em 1935), com um Instituto de Artes magnificamente estruturado, que em 1961/62 ele tentou recriar na universidade de Brasília. Dois golpes de Estado interromperam precocemente o funcionamento das duas universidades criadas pelo espírito dewiano de Anisio Teixeira: o Estado Novo (1937) e a Ditadura Empresarial/Militar (1964). A UDF foi fechada em 1939 pela vaidade pessoal do Ministro Capanema, que não queria competição com a Universidade que considerava sua, a Universidade do Brasil. Já a UNB não fechou mas mudou seu projeto e seus professores em 1965, quando demitiu mais de 200 professores, entre os quais estávamos eu e meu marido. Portanto a partir de 1939 até 1945 Anísio Teixeira foi perseguido político. Com a primeira queda política de Anísio, entretanto, a influência de John Dewey não foi eliminada.

Fomos moderadamente "dewianos", mesmo naquele tempo do Estado Novo porque nossas mais fortes influências institucionais no ensino da Arte no Brasil, o Teachers College da Columbia University de New York e o Instituto Jean Jacques Rousseau de Génève, para onde o governo mandava professores brasileiros e de onde recebia professores europeus eram grandemente influenciados por Dewey.

Dewey chegou ao Teachers College entre 1904 e 1906. Havia se demitido juntamente com sua mulher da Universidade de Chicago em protesto pela avaliação intelectual degradante das alunas mulheres, que a Universidade queria segregar em um College feminino de menos prestígio. Argumentavam que elas, pela sua inferioridade intelectual, estavam arruinando a imagem da instituição. O Teachers College, que o acolheu, evoluíra de uma instituição filantrópica criada pela feminista Grace Dodge para o desenvolvimento profissional de mulheres pobres, a Industrial Education Association, que rapidamente se transformou no New York College for the Training of Teachers e depois Teachers College. Portanto, por sua posição feminista, também rapidamente Dewey se torna o centro de atenções da instituição.

No Brasil a recuperação da Arte na Educação entre as duas ditaduras (1945 a 
1964) ainda está pouco estudada. Há muitos textos sobre a importância do Movimento das Escolinhas de Arte neste período, mas houve outras instituições que operaram positivamente na redemocratização e na ressignificação das influências de Dewey, inclusive a UNB já mencionada, o Colégio Andrews, a Escola Guatemala (pública).

Foi durante a ditadura de 64 sob o signo da militarização e da antidemocracia que a rejeição pela Escola Nova e a demonização de John Dewey se exacerbou. Aconteceu contra Dewey na Ditadura de 64 difamação semelhante a que está ocorrendo contra Paulo Freire hoje pelas hostes bolsonaristas. Acusações de elitismo, comunismo e coisas piores.

As Faculdades de Educação, inclusive a da USP, entraram na guerra contra a Escola Nova, John Dewey, Anísio Teixeira. Fui pessoalmente vítima de preconceito na USP por ser considerada escola novista e deweiana, quando sou várias outras coisas também. Sou antes de tudo pluralista, sem deixar de ser radical no sentido que Paulo Freire usa este conceito, opondo-o ao sectarismo. Foram criadas as pós-graduações em Educação, eliminando a leitura de John Dewey. Nos Estados Unidos também o prestígio de John Dewey diminuiu mas nunca chegou ao grau da rejeição brasileira.

Ao chegar nos Estados Unidos na Boston University em 1977 para fazer meu doutorado encontrei o terreno sendo fertilizado para a recuperação do ideário dewiano. A guerra do Vietnam havia mobilizado politicamente as universidades e a discussão do julgamento do impeachment de Nixon acirrado a crítica social e política. Eu estava estudando na primeira universidade de brancos que aceitou negros nos Estados Unidos, a universidade de Martin Luther King. Encontrei um jovem professor dando disciplinas sobre John Dewey analisando o aspecto fenomenológico de sua obra.

A velha paixão por suas ideias renasceu e escrevi minha tese analisando sob a Teoria da Dependência as influências de Walter Smith e John Dewey no Ensino da Arte no Brasil. No processo de pesquisa fui duas vezes a Génève, uma delas tendo até me hospedado na casa de Paulo e Elza Freire, e as conversas sobre Brasil e John Dewey eram intermináveis. Uma das grandes emoções nesse período foi visitar a cidade em que Dewey nasceu e viveu até seus 20 anos mais ou menos, Burlington, ao norte de Vermont, em pleno outono. Uma experiência estética com a natureza.

Ao voltar para o Brasil ainda vivíamos na Ditadura e não me animei sequer a traduzir e tentar publicar a tese, pois a depreciação de Dewey continuava.

Só com os inicios da redemocratização, em 1982, resolvi mandar traduzir a parte da tese sobre John Dewey pelos alunos dos cursos de tradução da PUC e da USP que se iniciavam e procurei a Editora Cortez.

Fui muito bem recebida por um dos consultores da editora, um educador muito inteligente, que chegou a ser importante gestor do MEC durante a retomada democrática. Ele me disse muito claramente:

"Olha, eu vou te contar uma coisa, eu estou arriscando porque confio em você, mas duvido muito que venda, pois há um total alijamento acerca de Dewey e isso é livro para Pós-Graduação, onde ninguém está estudando John Dewey". 
Então publicamos com o título de Recorte e Colagem e o subtítulo influência de John Dewey no ensino da Arte no Brasil. Será que inconscientemente eu queria esconder que se tratava de um livro sobre Dewey? O que me levou ao título foi meu processo de escrita. Não tínhamos domesticado os computadores ainda. Eles já existiam mas não eram democraticamente usados. Eu não datilografava, daí colocava grandes papeis no chão e ia recortando manuscritos e colando e escrevendo as frases que ligavam os textos já escritos e colados. O título também era uma metáfora culturalista: a ideia de recortes culturais reconfigurados em colagens adequadas à nossa cultura e não simplesmente cópia de ideias estrangeiras fora do lugar. Felizmente o livro não encalhou, mas ficou sozinho durante oito anos até que Maria Nazaré de C. Pacheco Amaral publicou sua tese intitulada Dewey filosofia e experiência democrática (1900). Embora não fosse sobre Arte me deixou feliz, pois não estava mais sozinha entre os da minha geração.

Mais feliz ainda fiquei quando uma jovem, Jociele Lampert, me procurou querendo fazer doutorado com minha orientação. Ela me impressionou muitíssimo pela inteligência e pela autonomia intelectual. Foi uma época que eu, como todo educador que escreve muito, fui perseguida por um grupo específico que via a Cultura Visual como novidade que deveria substituir a Arte nas escolas. O objetivo não era melhorar a escola, mas tomar o poder desta desempoderada disciplina que é Arte. Agora nem mais disciplina é, pois está sendo tutelada pela disciplina Língua Portuguesa num balaio de gatos chamado Linguagens. Na realidade voltou a ser atividade. Impressionou-me a coragem de Jociele me procurar para pesquisar Cultura Visual no momento em que os inimigos procuravam dizer que eu era contra a Cultura Visual. Eu já era ligada à Cultura Visual antes de se chamar Cultura Visual. Trabalhei com imagens e objetos da Cultura Visual e seus caminhos metodológicos, desde a política cultural que imprimi ao MAC quando o dirigi (1987 a 1993). As exposições Arte Periférica: cobogós, latas e sucatas; Estética do Candomblé; A Mata e Carnavalescos e suas propostas educacionais foram focadas na Cultura Visual do povo como tema, processo de curadoria e abordagem metodológica.

Jociele também se apaixonou pelas ideias de John Dewey. Hoje a vejo na liderança de um grupo que estuda, interpreta e debate as ideias filosóficas, estéticas, políticas e educacionais de Dewey e muito me orgulho dela, que fiel a seus valores educacionais fez seu Pós-Doutorado no Teachers College.

Quando encontro alunas/os muito interessados em assuntos que estudo geralmente pulo para outros interesses e fico feliz em ver que elas/es desenvolvem e ampliam os estudos que foram um dia meu foco. Por que pulo de interesse? Porque sou do tempo, como diz de mim o colega e amigo Ricardo Marin em um artigo da Revista Educação da PUC do Rio Grande do Sul, em que foi preciso me interessar por tudo, História, Filosofia, Psicologia, Metodologia, Política.

Éramos poucos há 64 anos quando comecei a estudar e trabalhar em Arte/ Educação. Hoje meus interesses estão mais centrados em Feminismo e Decolonização, mas reconheço que apesar de John Dewey ter voltado a ser leitura procurada por arte/educadores e artistas no Brasil depois da tradução para língua local do livro 
Arte como Experiência (2010) os estudiosos de sua obra têm muito que fazer ainda. Como dizem Erika de Andrade e Marcus Vinicus da Cunha, pesquisadores da USP, aos quais agradeço, no artigo (2016) A contribuição de John Dewey no ensino da arte no Brasil1:

\begin{abstract}
"A iniciativa tomada por Ana Mae Barbosa na década de 1980, ao trazer as concepções de Dewey para o cenário da arte-educação, carece de continuidade, pois o ensino da arte requer clareza sobre os temas que lhe são próprios: o que é o desenvolvimento humano, o que é a educação, qual é o sentido da arte no contexto em que se almeja a transformação educacional e social; quais recursos metodológicos podem ser postos em ação para que a arte seja instrumento efetivo no processo de conferir significado às coisas e, assim, formar o aluno em sintonia com o mundo contemporâneo." ${ }^{11}$
\end{abstract}

Completo este texto com outro que escrevi, 20 anos atrás num passado mais otimista para atualizar a bibliografia de John Dewey a pedido do meu querido editor, José Cortez.

\title{
Texto muito bibliográfico, numa "vibe" feliz, 2001
}

Recorte e Colagem: influência de John Dewey no Ensino da Arte no Brasil foi o título da primeira e segunda edições do livro John Dewey e o Ensino da Arte no Brasil.

A mudança de título que o editor e eu concordamos fazer não teve a intenção de enganar o leitor fazendo-o comprar um livro que já tenha sido lido, mas é resultado da morte dos preconceitos contra John Dewey. Seu nome em vez de vir a reboque depois de dois pontos agora lidera o título.

O livro batizado com nome mais justo talvez venha a ser relido com um outro olhar, um olhar renovado pelo interesse que John Dewey vem despertando na cultura internacional a partir da década de 1990.

Hoje vejo que o título anterior parece querer esconder que se trata de um estudo sobre John Dewey e para isto ressalta numa metáfora uma atividade diretamente ligada ao ensino da Arte: Recorte e Colagem. Assim o/a leitor/a procurado/a pelo título era somente o/a Arte/Educador/a. Apesar de meu entusiasmo por John Dewey, o título minimizava John Dewey como interlocutor da pesquisa. Sugeria, numa legítima defesa antecipada, que minha intenção era navegar pela história do ensino da Arte no Brasil, sendo John Dewey um acidente encontrado em meio à navegação. Talvez esteja sendo muito dura comigo mesma, mas o título original hoje me faz sentir covarde, amedrontada diante da desqualificação que sofria John Dewey no Brasil naquela época.

Quando escrevi esse livro, que é parte de minha tese de doutorado, o pensamento

1 Fernandes de Andrade, E. N., \& Vinicius da Cunha, M. A contribuição de John Dewey ao ensino da arte no Brasil. Espacio, Tiempo y Educación, 3(2), 2016, pag. 307. 
de John Dewey estivera em lenta e progressiva recessão nos Estados Unidos por quase duas décadas e consequentemente era tratado como velharia no Brasil.

Mudou o mundo, mudou a arte, mudou a educação e para repensar o nosso tempo, educadores, críticos de arte e até economistas têm buscado nas ideias de Dewey uma experimentação mais consciente da ação e uma construção de valores mais flexível culturalmente.

Ao longo dos 18 anos que se sucederam depois da publicação da primeira edição desse livro, muitos outros livros foram publicados sobre o pensamento de John Dewey. Principalmente nos Estados Unidos, novos pesquisadores se encarregaram de revelar aspectos de sua obra potencializados pelo tempo atual. Houve uma espécie de loteamento do pensamento de Dewey em setores especializados que vão da filosofia à arte, chegando até a assuntos do cotidiano político como a imigração, o racismo, puritanismo, etc.

As pesquisas contemporâneas sobre Dewey estavam apenas recomeçando quando escrevi esse livro, em 1977. J. Ann Boydston somente publicara os resultados de seu primeiro trabalho de edição das obras de Dewey, os 5 volumes que correspondem às obras iniciais de 1882 a 1898. Hoje terminada sua tarefa temos 37 volumes de obras de Dewey por ela editados e ainda há muitos textos dispersos de Dewey em arquivos de universidades americanas.

Em 1998, em uma pesquisa que realizei nos arquivos de Arte/Educação da Miami University, Ohio, (USA), encontrei dois textos de John Dewey datilografados que correspondem às palestras que proferiu, não consegui determinar com certeza se na própria Miami University ou na Penn State University. Os assuntos de que trata, através de sua crítica contundente, são de uma atualidade evidente: a submissão da educação aos interesses das finanças (hoje mais evidente com o neoliberalismo) e das indústrias e a submissão da criação à técnica (leia-se, para atualizar o assunto, em lugar de técnica, tecnologia).

Decidi mandar traduzir e publicar nesta edição como texto/epígrafe a palestra proferida por Dewey para professores de Arte e Trabalhos Industriais (no Brasil, em termos curriculares falava-se em Desenho e Artes Industriais), intitulada Cultura e Industria na Educação. Possivelmente deve datar dos fins dos anos 1940. A outra, Imaginação e Expressão, fica para um próximo livro ou uma próxima edição. ${ }^{2}$

No Brasil, com a política anti "Escola Nova" empreendida pelas Faculdades de Educação hegemônicas como as da Universidade de São Paulo, da Pontifícia Universidade Católica de São Paulo e da Universidade de Campinas, John Dewey, por ter sido inspirador do que pejorativamente se chamou no Brasil de "escola novismo", foi banido dos estudos educacionais. Passou a ser visto por muito tempo como defensor de uma educação elitista pelos que se consideravam renovadores e pela direita como um esquerdista americano que era preciso rasurar. Havia ainda os que se julgavam de esquerda e nacionalistas por recusarem qualquer influência americana

2 O outro inédito de Dewey está publicado no artigo: John Dewey sobre ideia e técnica em BARBOSA, Ana Mae. Redesenhando o Desenho: educadores, política e história. SP: Editora Cortez, 2015, pag. 385 a 392. 
e procuravam, para demonstrar seu esquerdismo, se associar ao pensamento e à pedagogia europeia, desprezando tudo que vinha dos Estados Unidos. Como se, do ponto de vista de identidade cultural, houvesse algum avanço em baixar uma bandeira colonizadora e levantar outra igualmente colonizadora.

O internacionalismo cultural de um Dewey e de um Foucault pode produzir sentido no sistema educacional brasileiro se respeitarmos as condições da ecologia cultural de nosso país, não importa que um seja americano e o outro francês. No diálogo cultural entre nações qualquer colonialismo deve ser rechaçado, como o colonialismo espanhol que dominou o desenho dos Parâmetros Curriculares do Brasil (1996 e 1997) e dos países do Mercosul por imposição de outra potência mundial que provavelmente calculou que colonialismo transversal é mais eficiente. Pensam que por sermos todos Latinos, entre salsa e samba escolheremos mesmo é Júlio Iglesias.

Parodiando um texto de Bourdieu, que circula na Internet, a luta que se trava hoje é: de um lado, potências comerciais que pretendem estender ao terceiro mundo seus interesses particulares de comércio; e do outro, uma resistência cultural fundada na defesa das obras universais produzidas pela "internacional desnacionalizada dos criadores". Há que distinguir entre os que querem ganhar dinheiro as nossas custas colonizando nossas mentes e àqueles, que longe do poder oficial, dizem suas palavras ao mundo e nos permitem interpretá-las e contextualizá-las.

Paulo Ghiraldelli, escreveu no primeiro número da Revista Teias (jan/jun. 2000), um artigo sobre Anísio Teixeira, no qual fala dos dias em que sobre ele era lícito dizer nos cursos de pós-graduação em Educação "não li e não gostei". Ghiraldelli aponta a mesma atitude desqualificadora por parte dos orientadores de tese dos anos 70 e 80, em relação a John Dewey, mestre de Teixeira. Atacados de tecnicistas e liberais pelos anti- americanistas de direita e pelos marxistas que não os leram, como diz Ghiraldelli, todos nós perdemos pela sonegação de seus textos, que longe de serem obviedades ditas de modo glamoroso, levam a pensar.

As ansiedades do pós-modernismo nos colocaram de volta a John Dewey, é o que nos dizem os autores escolhidos por Larry Hickman para escreverem em seu livro Reading John Dewey: Interpretations for a Postmodern Generation (1998).

Foi o pós-modernismo que recuperou John Dewey para as novas gerações de Educadores e Arte/Educadores, diferentemente do que diz José Mário Pires Azanha no desentusiasmado prefácio ao livro Dewey: Filosofia e Experiência Democrática de M. Nazaré de C. Pacheco Amaral (1990), quando valoriza o livro sobre Dewey porque é um clássico e os clássicos devem ser estudados, acrescentando que "a recusa dos clássicos é apenas uma opção arrogante pela superficialidade transvestida de modernidade (ou de pós-modernidade)".

Dewey não é somente importante porque é um clássico, mas porque antecipa inúmeros dilemas da condição pós-moderna com a qual nos confrontamos. Um deles é a recusa da História como Monumento, mas sua valorização como uma das resposta ao presente que destitui a ideia de progresso em História e recupera a noção de História como sintoma. 
É do próprio Larry Hickman o ensaio que recoloca Dewey no centro da Pedagogia Contemporânea caracterizada pelo questionamento. Tanto a Pedagogia do Questionamento como a Pedagogia Cultural conduzidas pelos teóricos e ativistas da Educação de hoje, devem muito a John Dewey, Paulo Freire e Vigotsky.

Analisando o livro de Dewey, The Theory of Inquiry (1938), Hickman mostra como são atuais suas ideias de que o questionamento é sempre situado em um contexto, e de que o questionamento só busca respostas para situações problemáticas realmente percebidas. Não adianta plantar artificialmente o problema, como se tenta fazer hoje sob a égide da pedagogia do projeto. Ainda mais, lembra que o questionamento não é para Dewey a busca da verdade pois da verdade absoluta ele desconfia, como dela desconfiam os educadores pós-modernos. Dewey concebe a verdade como a busca de algum acerto garantido dentro de um determinado contexto. Por isso considera o questionamento essencialmente social.

A ideia de que julgamentos não podem existir em separado dos contextos nos quais o questionamento tem lugar, que é sustentada por Dewey, ilumina a pedagogia pós-moderna.

Sua posição acerca do contextualismo do questionamento o leva a uma conceito de Ética que envolve a avaliação e resolução de reclamos conflitantes de valores experienciados. Dewey rejeita a noção tradicional de deveres e direitos fixos e julga que o atomismo moral levara a práticas sociais desastrosas. Posteriormente, aqueles que trabalharam como educadores na década de 70 e 80 , puderam comprovar que pouco resultou para a prática educativa da síndrome classificatória que pretendeu estabelecer estágios de comportamento, considerados como universais, portanto descontextualizados.

Pretendeu-se, quase sempre tomando Piaget como base, mapear classificatoriamente quase todas as atividades humanas como o desenvolvimento religioso (Fowler, 81), o desenvolvimento social (Selman, 80), o desenvolvimento do eu (Loevinger,78) e finalmente o desenvolvimento moral (Kohlberg, 81). Kohlberg, implicitamente advoga a ideia que normas éticas existem antes da experiência e que se impõem sobre uma situação independentemente do contexto social. Kohlberg, apesar do empirismo, mas conduzido pela ansiedade de traçar estágios de evolução moral subscreve implicitamente a ideia da aplicação de eternas virtudes à solução de problemas em idades determinadas.

Gregory Papas analisa o texto de Dewey Ethics: Morality as Experience mostrando como o autor está longe de subscrever a ideia acima descrita, que em resumo coloca a experiência sob o domínio de normas pré-estabelecidas mas também está longe de aceitar a ideia da arbitrariedade da norma ética. De acordo com Papas, Dewey reclamava "por uma ética que colocasse o centro de gravidade moral dentro do processo de vida e não dentro de uma torre de marfim".

Charlene Haddock Seigfried que escreve o artigo John Dewey's Pragmatist Feminism, identifica na crítica de Dewey ao patriarcalismo previsões de mudança que coincidem com as aspirações do movimento feminista. Em um artigo de Dewey, escrito após a Primeira Guerra Mundial no qual clama por uma ética feminista adequada 
as realidades do pós-guerra, Seigfreid chega a pinçar a seguinte frase "mulheres nunca fizeram tão pouco uso de maridos como agora na França e na Alemanha" , uma ironia pouco em voga naquele tempo. Respeito às diferenças é um valor intrínseco ao conceito de Democracia de John Dewey.

Charlene Seigfried antes da publicação desse artigo escreveu o livro, Reweaving the Social Fabric: Pragmatism and Feminism (1996), pondo em destaque a participação de Dewey na luta feminista não só no campo das ideias e mas também na ação. Lembra que o pedido de demissão de Dewey da Universidade de Chicago fora provocado por duas crises que envolveram mulheres, seus direitos e respeito ao seu trabalho. A primeira, em 1902, foi uma proposta de segregação de mulheres. A Universidade já tinha, naquela época, $40 \%$ de alunas mulheres quando o presidente da Universidade decidiu segregá-las em um College separado, alegando que a Universidade estava se feminilizando e portanto desencorajando os homens a frequentá-la, o que evitava que a Universidade se tornasse uma prestigiosa instituição de pesquisa. Em resumo, pensavam que a admissão de mulheres em igual termos estava mediocrizando e mal afamando a Universidade. John Dewey foi um dos líderes de um protesto do qual participaram todas as professoras mulheres da Universidade. Poucos professores importantes homens tiveram coragem de assinar os manifestos. A outra crise foi a perda de autonomia da Escola Laboratório que ele criara e sua incorporação à administração da Universidade. Os que protestavam, como sua esposa Alice Chipman Dewey que era naquela momento diretora da Escola Laboratório, foram demitidos. Com a incorporação, a Escola Laboratório se tornou uma escola qualquer, uma escola comum. Como não havia documentos que comprovassem que a luta fora ideológica, que se estava tentando diminuir o poder e a visibilidade das mulheres que comandavam a Escola Laboratório os inimigos de Dewey o acusaram de estar defendendo apenas interesses pessoais, reduzindo seu pedido de demissão a um protesto pela demissão da mulher.

Mas suas posições multiculturais estavam fundadas na recusa aos preconceitos que se disfarçam em hábitos como deixa claro no artigo de 1940, Contrary to Human Nature, no qual reverbera contra o anti-semitismo e o racismo anti-negritude nos Estados Unidos. ${ }^{3}$

O livro de Hickman traz ainda mais nove artigos que demonstram, entre outras coisas, como as ideias de Dewey são relevantes hoje para o conceito de comunidade e educação comunitária (James Campbell) para o pensamento político (John Stuhr) para a filosofia da Religião (Steven Rockefeller) e para a Arte (Thomas M. Alexander).

Alexander demonstra como a ideia de Experiência formulada por Dewey se transformou em nossos dias num adequado conceito de arte. É entretanto no livro que Alexander publicou em 1987, John Dewey's Theory of Art, Experience and Nature: The Horizons of Feeling, que ele vai muito mais além na demonstração da pós-modernidade de Art as Experience. Nessa obra analisa as posições contraditórias de Dewey acerca da arte, de um lado naturalista em Experience and Nature e de

$3 \bigcirc$ que hoje chamamos racismo estrutural, machismo estrutural, etc. 
outro lado pragmatista em Art as Experience, um de seus últimos livros, publicado aos 75 anos. As duas posições analisadas por Alexander correspondem a uma grande ruptura na História da Arte. Nos primeiros anos de Dewey como intelectual a Arte era considerada representação da Natureza, do mundo ao redor, da "realidade", daí sua postura em favor do desenho de observação como o melhor caminho para desenvolver a capacidade de ver e representar. Embora começando a ser entendida como antinatureza no Impressionismo a Arte do século XX, principalmente no novo mundo, só passa a se configurar como Expressão quase duas décadas depois, quando se liberta definitivamente do comando naturalista/realista. É em função do modernismo e já respondendo e se opondo ao conceito modernista de expressão que Dewey constrói a teoria da Arte como Experiência.

Dewey, como já observaram Benedetto Croce, Pepper e mais recentemente Richard Bernestein e Richard Rorty, se opunha aos primeiros conceitos modernistas de Expressão, isto é, não considerava a expressão uma descarga de sentimentos articulada pela forma, mas uma clarificação das emoções. Para ele a dinâmica ecológica da Experiência Estética transforma a energia orgânica sem sentido em expressão significante.

- movimento de tensão e resistência da experiência estética de quem faz (do artista) e de quem aprecia (intérprete) reorganiza a consciência e gera re+conhecimento. Portanto para Dewey a percepção é em si mesma essencialmente uma categoria estética em lugar de epistemológica. Em alguns pontos seu conceito de reorganização da consciência em função da experiência estética se assemelha a ideia da ordem oculta da Arte do psicanalista Anton Ehrenzweig mas foge das "lamurias psicologizantes" que caracterizaram as interpretações da Arte nos inícios do Modernismo.

Talvez por isso, Robert Morris (2000) chega a afirmar que embora pouco citado pelos críticos de Arte é o empirismo Deweyano que justifica a defesa da autonomia da obra de Arte que fundou o minimalismo.

Trata-se de uma interpretação parcial do empirismo Dewiano que, ao contrário do minimalismo, admitia a contextualização da experiência.

Curiosamente o livro de Jerome Popp, Naturalizing Philosophy of Education: John Dewey in Postanalytic Period (1998) argumenta que diferentemente de outros empiristas que afirmavam que dados científicos, principalmente da psicologia não tinham lugar na filosofia, Dewey aceitava o que era conhecido sobre inteligência e processos cognitivos para justificar métodos, aceitação que o aproxima dos filósofos da ciência de hoje mas o distancia em Arte dos críticos expressionistas.

O filósofo Richard Rorty, com frequentes referências, análises, reconfigurações das ideias de Dewey, foi um dos maiores responsáveis pelo seu renascimento.

O novo interesse pelas obras de John Dewey levou James Campbell, um pesquisador que desde os anos 80 vem estudando John Dewey a publicar o livro Understanding Dewey, valioso para as novas gerações entenderem as ideias de Dewey no contexto atual. 
Para Raymond D. Boisvert, que escreveu John Dewey: Rethinking our time, a melhor designação para Dewey não é "moderno" nem "pós-moderno". Ele foi "polytemporal", termo tomado de empréstimo a Bruno Latour.

Em 1998 foi publicado a livro John Dewey and the Lessons of Art. Seu autor, Philip W Jackson, pretendia aclarar o conceito de Experiência de Dewey principalmente para professores e demonstrar como a Arte nos ajuda a viver melhor a vida cotidiana. Ele se pergunta: Como professores de todas as áreas poderão fazer uso de "lições" de Arte (entendidas em termos experienciais) para melhorarem o seu ensino?

Pretendeu responder à pergunta, mas nos deixou ainda na sala de espera. Uma certa insistência em autoajuda é monótona e fora de foco.

O paradoxo é que Art as Experience é o livro mais complexo de Dewey e o menos estudado, talvez por ter sido publicado quando o escritor já velho, afastado da mídia, não tinha um prestígio público tão evidente quanto antes. Talvez isto tenha sido bom para essa obra em especial.

Não serviu de presa fácil para intelectuais vicários, aqueles que usam o recurso de escrever sobre alguém famoso e polêmico para se contaminar com a fama que a polêmica gera.

Agora, os que escrevem sobre John Dewey já não correm o perigo de serem discriminados pelos pedagogos brasileiros como eu o fui quando publiquei este livro, que Walter Garcia audaciosamente aprovou para publicar pela Editora Cortez.

\section{Referências}

BARBOSA, Ana Mae. John Dewey e o ensino da Arte no Brasil. SP: Cortez, 2011, $7^{a}$ edição, pag. 13-32.

FERNANDES de Andrade, E. N., \& VINICIUS da Cunha, M. A contribuiç̧ão de John Dewey ao ensino da arte no Brasil. Espacio, Tiempo y Educación, 3(2), 2016, pág. 301-319. doi: http://dx.doi.org/10.14516/ete.2016.003.002.013

Atualização bibliográfica de 1977 ao fim de século XX:

AMARAL, M. Nazaré de C. Pacheco. Dewey: Filosofia e Experiência Democrática. São Paulo: Editora Perspectiva, 1990.

ARCILLA, Rene Vicente. For the love of perfection: Richard Rorty and Liberal Education. New York: Routledge, 1995.

AREHART, Cathy. "Pepper's categories, Dewey's Contextualism and The Black Aesthetic". Paunch, ns. 36 e 37, Abril, 1973. 
ARLISS, Rebecca M. "The Dissertation as a Learning Experience". Insights n²3, Dezembro, 1987, pág. 6-7.

ATKINSON, Glen. "Institutional Adjustment Instrumental Efficiency and Reasonable Value". Journal of Economic, n²4, 1990, pág. 1095-1107.

ATKINSON, Harley. "Dewey's Process of Reflective Thinking and Christian Education" Christian Education Journal, n²9,1989, pág. 17-29.

ATKINSON, Lilian. "Teachning Morality in the Schools". Illinois Schools Journal n 62, 1982, pág74-84.

AUXIER, Randall E. "Dewey on Religion and History". Southwest Philosophy Review, $n^{\circ}$ 6, 1990, pág. 45- 58.

AYERS, William. "Problems and Possibilities of Radical Reform: a teacher educator reflects one making change", Peabody Journal of Education n 65, Inverno,1988, pág. 35-49.

"Rethinking the Profession of Teaching: a progressive option action" in Teacher Education n 12, 1990, pág 1-5.

BALDWIN, John - George Herbert Mead: A Unifying Theory of Sociology. Beverly Hills, California: Sage Publications, 1988.

. "Advancing The Chicago School of Pragmatic Sociology", Sociological Inquiry, 1990, pág. 1-27.

BARBOSA, Ana Mae. John Dewey e o ensino da Arte no Brasil. SP:Cortez, 2011, $7^{\text {a }}$ Edição, 200 pgs.

BARNES, Nora Ganim. "What Dewey Didn't Tell us: A closer look at our basic assumptions in marketing Health Services", Journal of Health Marketing n 5, Outono, 1985, pág. 59-61.

BARTOCK, Geoffrey Herman - The Minds and the Masses, 1760 - 1980, London: George Allen and UNWIN, 1984.

BAUER, Norman. "Toward a Multiple Option Society", Insights n²2, Maio, 1992, pág. 4-5.

BEANE, James A. Affect in the Curriculum, Toward Democracy, Dignity and Diversity, New York: Teachers Collage Press, 1990.

BEDFORD, David. "John Dewey's Logical Project" Journal of Pragmatics, n 19, 1993, pág. 453-68.

BEATTIE, Catherine. "Judging the Worth of Curriculum Materials" Journal of Curriculum Studies, n¹8, 1986, pág. 299-309.

BEINEKE, John A. "The Investigation of John Dewey by the FBI" Educational Theory, $\mathrm{n}^{\circ}$ 37, 
1987, pág. 43-52.

"William Heard Kilpatrick's, final years at the Teachers" College Educational Theory, n³9, 1989, pág. 139-49.

BENITEZ, Mario A. "What is Wrong with Teaching in Higher Education?", in James Van Patten (ed), Understanding the Many Faces of the Culture of Higher Education, Lewinston, New York: Edwin Press, 1993, pág. 85-106.

BENNETT, James O. "Dewey on Causality and Novelty". Transactions of the Charles S. Pierce Society, $n^{\circ} 16,1980$.

BENSON, Karen. "Through Conflict and Emotion Towards Community, Would John Dewey Agree?", Proceedings of Far Western Philosophy of Education Society, pág. 33-40, 1992.

BENSON, Kathryn. "Clinton and Reform: Practical Solutions for Particular Problems" Insights, n²8, Dezembro, 1992, pág. 5-6.

BENTON Center for Curriculum and Instruction. "Two Portraits of Dewey, An Historical Tale" Report from the Center, University of Chicago, n 5, Inverno, 1999, pág. 1-5.

BERDING, Joop W.A. "In a Deweyan Spirit: a Dutch View on the Case of Minority Groups", Insights, n² 28, Julho, 1992, pág. 6-7.

BERNSTEIN, Richard Jacob. "Dewey Democracy: the Task Ahead of US". In John Rajchman and Cornel West (ed), Post-Analytic Philosophy NewYork, Columbia University Press 1985, pág. 48-59.

"The Resurgence of Pragmatism." Social Research, n 59, Inverno 1992, pág. 813-40.

The New Constellation: The Ethical-Political Horizons of Modernity-Post Modernity. Cambridge: MIT Press, 1992.

BOISVERT, Raymond D. John Dewey Rethinking Our Time. New York State University of New York Press, 1998.

BOYDSTON, Jo Ann. The middle works of John Dewey, 1899-1924, Carbondale: Southern Illinois University Press, 1983.

The Later Works of John Dewey, 1925 - 1953, Carbondale: Southern Illinois University Press, 1989.

BOWERS, C.A. Elements of a Post-Liberal Theory of Education, New York, Teachers College Press, 1987.

Education, Cultural Myths and the Ecological Crises, Albany: State University, of New York Press, 1993. 
BREESE, Dave. "The Vast Emergence: John Dewey in his seven men who rule the world from the grave", Chicago: Moody Press, 1990, pág. 151-77.

BROUDY, Harry Samuel. "Truth and Credity: The Citizen's Dilemma", J. Dewey Society Lectures Series, $\mathrm{n}^{\circ}$ 17, New York, Longman, 1981.

BRUBACHER, John W., Charles W. Case and Timothy G. Reagan. Becoming a Reflective Educator: How to Build a Culture of Inquiry in the Schools. Thousand Oaks, California: Corwin Press, 1994.

BRUNER, Jerome. "Language and Experience", in R.S. Peters, John Dewey Reconsidered. London: Routledge and Kegan Paul, 1977.

CAMPBELL, James. Understanding John Dewey. Chicago: Open Court, 1996.

DEARBORN, Mary V. Love in the Promised Land: The story of Anzia Yezierska and J. Dewey, New York: Free Press, 1988.

DEEGAN, Mary Jo. Jane Addams and the Men of the Chicago School, 1892-1918, New Brunswick, New Jersey: Transaction Books, 1988.

GAVIN, William. Context over Foundation: Dewey and Marx Dordrecht, Holand: D. Reidel Publishing Co., 1988.

GHIRALDELLI, Paulo. Anísio Teixeira - o nosso pragmatista do século XX fazendo filosofia no começo do século XXI em Revista Teias: Rio de janeiro Faculdade de Educação / UERJ, Ano 1, Num 1, jan./jun. 2000, pág. 119-123

HASKINS, Casey and SEIPLE, David I. Dewey Reconfigured: essays on deweyan pragmatism. New York: State University of New York Press, 1999.

HICKMAN, Larry A (ed.) Reading Dewey: Interpretations for Postmodern Generation. Bloomington and Indianapolis: Indiana University Press, 1998.

JACKSON, Philip W. John Dewey and the Lessons of Art. New Haven and London: Yale University Press, 1998.

MORRIS, Robert. Size Matter. Critical inquire, volume 26, número 3 Primavera, 2000 pág. 474-487

POPP, Jerome A. Naturalizing Philosophy of Education: John Dewey in the Post Analytic Period. Carbondale: Southern Illinois University Press, 1998.

SEIGFRIED, Charlene Haddock. Pragmatism and Feminism. Chicago \& London: The University of Chicago Press, 1996.

STUHR, John. Philosophy and Reconstruction of Culture, Albany: State University of New York Press, 1993. 
Além dessa bibliografia são importantes também os números monográficos de revistas como:

The Resurgence of Pragmatism da Social Research vol 59, Inverno, 1992, pág. 813-40.

Rorty, Dewey and Post Modern Metaphysics da Southern Journal of Philosophy, vol 27, 1989, 173-92.

O Council for Research in Music Education publicou (n93) no verão de 87 uma avaliação da influência de Dewey na Educação Musical.

Submissão: $28 / 07 / 21$

Aceitação: 29/07/21 